\title{
Los saberes maternos y la atención de enfermedades diarreicas e infecciones respiratorias agudas en Ocotepec, Chiapas
}

\author{
RENATA GABRIELA CORTEZ GÓMEZ
}

Desde la perspectiva de la epidemiología sociocultural, se analiza cómo en Ocotepec, Chiapas, los saberes maternos sobre las enfermedades diarreicas y las infecciones respiratorias agudas, estudiados a partir de las representaciones sociales y prácticas de atención, inciden en la búsqueda de atención apropiada. Los resultados demuestran que no hay un reconocimiento de los signos de alarma de deshidratación y neumonía, las complicaciones más graves, lo que causa defunciones en niños menores de cinco años que pudieron evitarse con tratamientos adecuados, que no fueron accesibles debido a los procesos de medicalización y mercantilización de las prácticas médicas locales, y la falta de acceso a los servicios públicos de salud.

PALABRAS CLAVE: saberes maternos, infección respiratoria aguda, enfermedad diarreica aguda, niños menores de cinco años, muerte de niños menores de cinco años

Mother's Health-Related Knowledge and the Treatment of Diarrheal Disease and Acute Respiratory Infection in Ocotepec, Chiapas

How mothers' health-related knowledge avoids the use of appropriate medical treatment for diarrheal disease and acute respiratory infection in Ocotepec, Chiapas, is analyzed from a sociocultural epidemiology approach, focusing in their social representations and practices of treatment. The results demonstrate that the "danger signs" of the most severe threats of those illnesses: dehydration and pneumonia, are not recognized. This problem leads to children deaths due to the lack of use of appropriate treatment, that was not reachable because of the processes of medicalization and commodification of the local medical practice, and the lack of access to public medical attention.

Renata Gabriela Cortez Gómez

Centro de Investigaciones y Estudios Superiores en Antropología SocialCiudad de México, México jatzobudano@hotmail.com
KEYWORDS: mothers' health-related knowledge, acute respiratory infection, diarrheal disease, under five children, under five mortality 
asta 2015, cada día 16000 niños menores de cinco años morían en el mundo por causas susceptibles de ser prevenidas, entre ellas, la diarrea y la neumonía (ONU, 2015). En México, entre 1980 y 2005, las estrategias gubernamentales ya habían favorecido la disminución de las tasas de mortalidad por diarrea en 93\%, y por infecciones respiratorias en 86\% (Tapia, 2007); sin embargo, hasta 2010 estos padecimientos ocasionaban $8 \%$ de las defunciones en niños menores de un año y 13\% en preescolares (INEGI, 2016). A menor escala, el panorama era más preocupante en poblaciones como el municipio de Ocotepec, Chiapas, pues ocasionaban más de 50\% de las defunciones en esos grupos de edad. Diversos estudios afirman que la falta de reconocimiento de los signos de alarma retrasa la atención oportuna de los padecimientos, a lo que hay que agregar la inadecuación o insuficiencia de los tratamientos que emplean los cuidadores (Álvarez-Larrauri, 1998; INSP, 2012; Unicef y WHO, 2006), lo que puede ocasionar finales funestos.

El objetivo de este artículo es analizar cómo los saberes maternos respecto a las enfermedades diarreicas y las infecciones respiratorias agudas han contribuido a la configuración de las trayectorias de atención de los niños ocotepecanos que murieron por estas causas entre 2005 y $2010 .{ }^{1}$ La intención no es responsabilizarlas de las defunciones, sino demostrar cuáles eran los recursos disponibles y asequibles cuando sus hijos enfermaron y qué factores intervinieron en su uso. Para ese fin, recurro a la epidemiología sociocultural (Haro, 2008; Hersch-Martínez, 2013), propuesta teórico-metodológica que trata de rescatar los factores culturales-ideológicos, políticos y socioeconómicos que hacen del padecimiento y la muerte construcciones socioculturales que rebasan su dimensión biológica y clínica.

$1 \quad$ Este artículo reúne parte de los resultados de mi tesis doctoral, en la que demostré que, además de los saberes maternos, otras determinantes socioculturales que incidían en la configuración de las trayectorias de atención de niños que fallecieron por estas causas en Ocotepec eran la desigualdad económica, la violencia de género y la falta de redes de apoyo (Cortez, 2015). 


\section{La mortalidad en Ocotepec como indicador de desigualdad social}

Las estrategias implementadas en México desde la década de 1980, como la provisión de sales de rehidratación oral (SRO); las semanas nacionales de vacunación; los programas de prevención, diagnóstico y tratamiento de enfermedad diarreica e infección respiratoria aguda y prevención de la desnutrición; Agua Limpia y Piso Firme, así como Arranque Parejo en la Vida, han incidido de manera positiva en la disminución sostenida de la tasa de mortalidad de niños menores de cinco años (TMN; Tapia, 2007; INSP, 2012), ${ }^{2}$ la cual, de 41 en 1990, descendió a 15 en 2015 (The World Bank, 2015; Unicef, 2014).

En el nivel nacional, hasta 2010 se observaba que las muertes debido a afecciones del periodo perinatal, malformaciones congénitas, accidentes y tumores malignos habían desplazado a las ocasionadas por enfermedad diarreica aguda (EDA) o infección respiratoria aguda (IRA). Por lo tanto, evitar muertes infantiles y preescolares ${ }^{3}$ es un reto que requiere infraestructura médica, a veces sofisticada, para atender a las mujeres durante el embarazo y alumbramiento, y a los bebés desde que nacen y conforme se desarrollan.

Así, la mortalidad de los menores de cinco años es reflejo de los éxitos, limitaciones y deficiencias del sistema de salud, y también es un mirador de las profundas desigualdades que prevalecen en el país, pues a los nuevos retos se siguen sumando los viejos problemas, como la alta proporción de muertes evitables en ciertas poblaciones.

En 2010, la desigualdad de la mortalidad de menores de cinco años en Ocotepec, Chiapas, respecto a la tendencia nacional, se expresaba de tres formas: a) la TMN del municipio era de 40.5 (CEIEG, 2014), mientras la nacional era de 17 (The World Bank, 2015); b) las defunciones de menores de cinco años representaban $32.2 \%$ de las muertes totales de la localidad (bases de datos propias), ${ }^{4}$ que

contrastaba con el 5\% que representaban en el nivel nacional (Fernández, Hernández y Viguri, 2013); c) en el país, más de 70\% de las muertes de menores de un año obedecían a afecciones del periodo perinatal y malformaciones congénitas (INEGI, 2016), que en Ocotepec representaron apenas 20\% (bases de datos propias). En este municipio, las IRA, EDA y enfermedades nutricionales representaron $60 \%$ de las defunciones en menores de un año y más de 50\% en los preescolares (bases de datos propias); mientras que en el ámbito nacional las tres primeras causas de muerte en preescolares son los accidentes, las malformaciones congénitas y los tumores malignos, con 46\% (INEGI, 2016).

La epidemiología sociocultural sostiene que los daños sanitarios responden a determinantes políticoeconómicas, ambientales y socioculturales (Haro, 2008; Hersch-Martínez, 2013). Por lo tanto, la enfermedad y la muerte no pueden verse sólo como hechos biológicos, sino como procesos moldeados por la respuesta social que organiza su atención o desatención.

De acuerdo con Menéndez (1990), la vía más accesible para conocer cómo los sujetos o grupos hacen frente a dichos procesos es partir de los saberes que desarrollan con la finalidad de solucionarlos de manera provisional o definitiva. Esto se denomina autoatención, un tipo de práctica médica que no se reconoce como tal pero es legítima, pues constituye el "primer nivel real de atención" y es parte de

2 antes de cumplir los cinco años y se estima en función de mil nacidos vivos.

3 En la demografía se establecen diferencias entre la muerte en niños menores de un año, lo que se conoce como mortalidad infantil -infant mortality-, y la muerte en niños que tienen de uno a cuatro años de edad, lo que se denomina mortalidad preescolar. La que ocurre en ambos grupos en conjunto se denomina muerte de niños menores de cinco años - under-five mortality-.

$4 \quad$ Datos obtenidos del análisis en SPSS de las bases de datos sobre defunciones, de 2005 a 2010 (DGIS, 2016). 


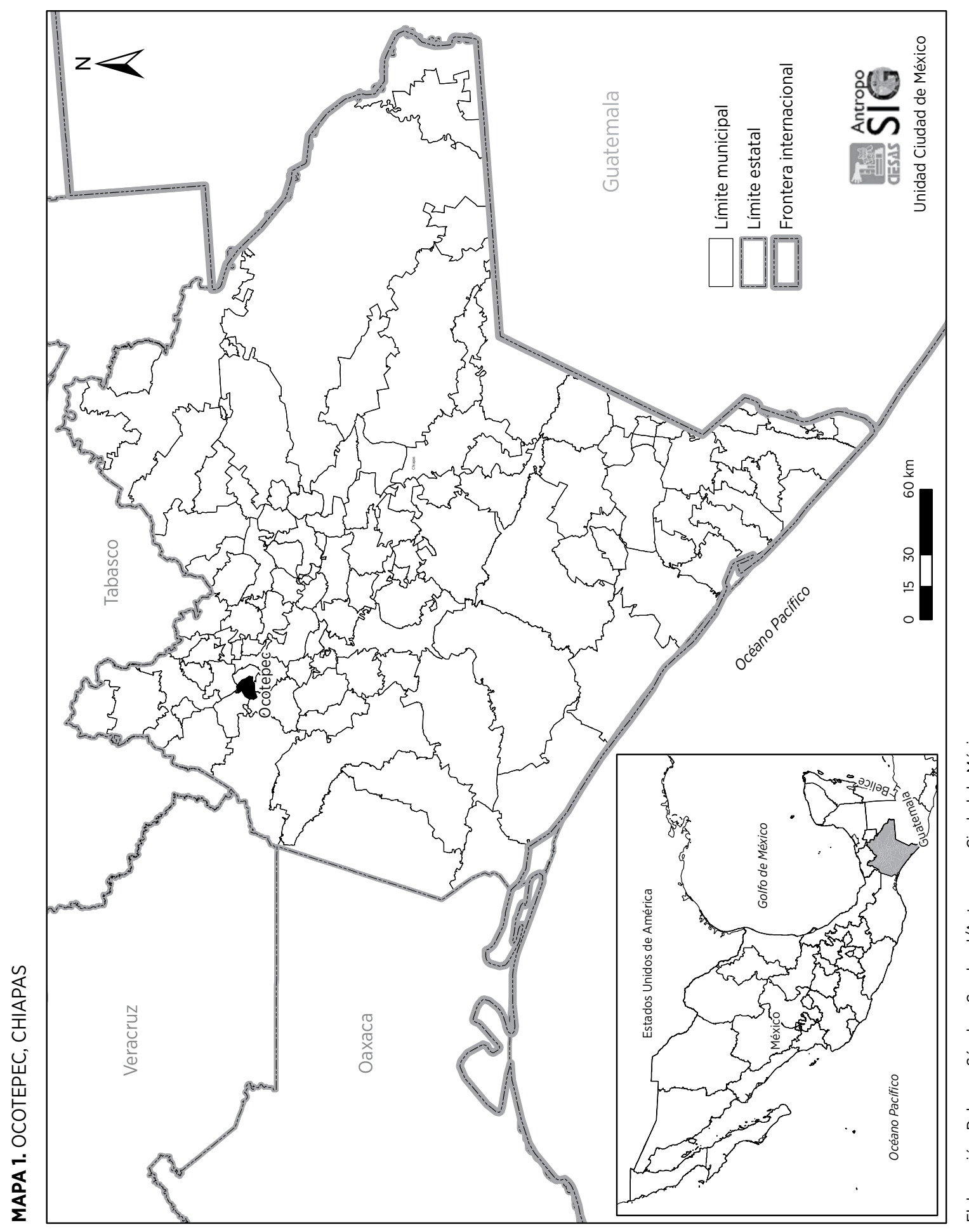

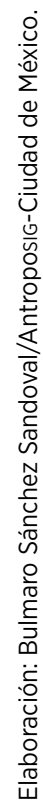


la carrera del enfermo (Menéndez, 1990) o la trayectoria de atención.

La autoatención tampoco se considera parte del sistema de salud, ${ }^{5}$ inherente a toda sociedad, y las acciones que llevan a cabo las personas son calificadas por los especialistas como equivocadas o nocivas, pese a que los organismos internacionales, desde la década de 1980, han promovido el que la sociedad civil se hiciera cargo de las actividades de autocuidado y automedicación (Menéndez, 1990). Muchas de estas actividades se referían a la atención de las EDA e IRA, e involucraban principalmente a las mujeres, quienes en muchas sociedades han asumido el papel de cuidadoras de los más pequeños (Osorio, 2001; Menéndez, 1990).

Coincido con Menéndez (1990) en que el análisis de estos saberes, que se traducen en las representaciones sociales y prácticas de atención de los padecimientos infantiles, es una de las vías para profundizar en por qué y cómo mueren los niños en Ocotepec, Chiapas. Las madres son las primeras en detectar que el niño está enfermo y quienes deciden qué tipo de atención médica proporcionar en función de los recursos disponibles y accesibles — por razones económicas, ideológicas, geográficas y técnicas-; por lo tanto, es importante conocer todos los factores que intervienen en el uso o ausencia de uso de alguno de estos recursos, lo que determina desenlaces funestos en ciertos casos.

\section{El contexto de indagación: Ocotepec, Chiapas}

Ocotepec se ubica en la Sierra Madre de Chiapas. Hasta 2012 estaba entre los 125 municipios del país con menor índice de desarrollo humano (IDH, INEGI, 2013). Una proporción de $94.7 \%$ de la población se encontraba en situación de pobreza (Coneval, $2012)^{6}$ y el promedio de escolaridad de la población general era de cuatro años. Tiene un total de 11878 habitantes, con $82 \%$ de hablantes de zoque, de los cuales 28\% es monolingüe (INEGI, 2011; 2013). ${ }^{7}$

La alta tasa de natalidad casi, de 28.89 nacimientos por cada mil mujeres, se combina con $15 \%$ de hijos fallecidos, casi el doble de las cifras estatales y nacionales, de 9 y $8 \%$ respectivamente (INEGI, 2011). Sin embargo, el personal de salud informó que, en 2014, 96\% de los niños contaba con el esquema de vacunación completo y que el programa de planificación familiar poco a poco tenía más aceptación, con 150 usuarias permanentes de métodos anticonceptivos inyectables y un promedio de 15 mujeres que se hacen la salpingoclasia cada año (entrevista con enfermera del IMSS-Oportunidades, Ocotepec, Chiapas, 26 de noviembre de 2013).

El municipio cuenta con tres unidades médicas de primer nivel, dos del Instituto Mexicano del Seguro Social (IMSS-Oportunidades) y una del Seguro Popular. De las primeras, hay una en la cabecera municipal, conocida por los informantes como "la clínica”, cuyos programas prioritarios son: planificación familiar; atención prenatal, del puerperio y del recién nacido; prevención de cáncer cérvicouterino y muerte materna; vigilancia de la nutrición

La definición de sistema de salud de Kleinman rebasa la prestación de servicios profesionales, pues incluye "los patrones de creencias acerca de las causas del padecimiento; las normas que determinan la elección y la evaluación del tratamiento; los estatus socialmente legitimados, los roles, las relaciones de poder, los patrones de interacción y las instituciones" (1980: 24).

6 El Consejo Nacional de Evaluación de la Política de Desarrollo Social (Coneval, 2012) define la pobreza como el no disponer de ingresos suficientes para comprar la canasta alimentaria y no alimentaria, además de al menos una carencia social que puede ser: a) rezago educativo; b) acceso a los servicios de salud; c) acceso a la seguridad social; d) calidad y espacios en la vivienda; e) acceso a los servicios básicos en la vivienda, y f) acceso a la alimentación.

7 En Chiapas hay 57075 hablantes de zoque, distribuidos en 17 municipios, que representan $5 \%$ de la población indígena del estado (INEGI, 2011; 2013). 
y el crecimiento infantil; manejo de casos de diarrea; tratamiento antiparasitario de las familias; manejo de infecciones respiratorias agudas; prevención y control de la tuberculosis pulmonar y diabetes mellitus, y prevención de accidentes y manejo inicial de lesiones. La atención se otorga en el servicio de consulta externa general o con citas programadas. El Hospital General Regional de Tuxtla Gutiérrez, a unos $110 \mathrm{~km}$ de distancia, y el Hospital Rural del IMSS-Oportunidades, de Ocozocoautla de Espinosa, a unos $125 \mathrm{~km}$ de distancia, constituyen el segundo nivel de atención. La referencia se hace ante urgencias, como partos de alto riesgo y accidentes, así como consultas externas de especialidad (entrevistas con médica y enfermera de la unidad médica rural, Ocotepec, Chiapas, 20 de diciembre de 2012 y 26 de noviembre de 2012, respectivamente).

\section{Metodología}

En 2008 trabajé en Ocotepec como promotora de una organización no gubernamental (ONG), lo que me permitió conocer la alta prevalencia de desnutrición infantil, problema que estudié en mi investigación de maestría. Con esta experiencia, detecté que la muerte de los niños era un evento frecuente, lo que confirmé con datos de instituciones oficiales que demostraban que hasta 2010 Ocotepec estaba entre los municipios chiapanecos con alta tasa de mortalidad infantil y de menores de cinco años (CEIEG, 2014; Conapo, 2011; INEGI, 2004).

Al revisar los certificados de defunción del registro civil y las bases de datos de mortalidad del Sistema Nacional de Información en Salud (bases de datos propias), determiné que entre 2005 y 2010 las principales causas de muerte fueron las IRA y EDA. Intenté contactar a las familias por medio de las actas de defunción, pero no fue posible hablar con ellas al respecto porque les producía dolor y recordaban problemas que rebasaban la atención clínica, algunos de los cuales no habían resuelto. Por ello, preferí usar la técnica de bola de nieve. Así contacté a cinco familias que vieron morir al menos a un menor de cinco años por estas causas entre 2005 y 2010 para tener recuerdos fiables y al mismo tiempo menos dolorosos. Estas cinco familias eran originarias de la localidad y accedieron a colaborar en la investigación. También recurrí a informantes secundarios para triangular la información cuando era insuficiente y conté con la colaboraron de diez terapeutas. $^{8}$

Esta investigación se planteó desde una perspectiva cualitativa y utilizó el método etnográfico. Durante el año en que viví en Ocotepec, pude hacer observación participante de las prácticas de atención

Los ocotepecanos reconocen los siguientes tipos de terapeutas: a) doctor: son los médicos de "la clínica", quienes emplean sólo recursos curativos farmacológicos, tecnológicos y técnicos de la medicina científica; b) enfermera: una de ellas trabaja en el turno de lunes a viernes, es originaria de la localidad y hace de traductora cuando se requiere; la del turno del fin de semana no habla zoque; ambas ejecutan los programas de salud mientras los médicos están en consulta; c) practicantes: son los que tienen conocimientos de medicina tradicional pero decidieron colaborar como auxiliares de salud de "la clínica" durante algunos años, después de los cuales abrieron sus propios consultorios privados; la mayor parte de sus recursos curativos son alópatas, aunque también utilizan medicina naturista; d) parteras: éstas, aunque tienen conocimientos de medicina tradicional, desde hace 40 años reciben entrenamiento del Imss y la Comisión Nacional para el Desarrollo de los Pueblos Indígenas (CDI, antes Instituto Nacional Indigenista, INI), de donde aprendieron a usar recursos alópatas que, combinados con los tradicionales - hierbas, sobaduras, limpias, etc.-, emplean en la atención del parto y los padecimientos infantiles; e) hueseros: éstos mezclan recursos tradicionales - sobadurasy alópatas - antiinflamatorios orales o inyectables- para curar traumatismos leves y luxaciones; f) curanderos o yerbateros: son los que emplean recursos tradicionales - hierbas, limpias, brebajes, etc.- para curar una diversidad de padecimientos, aunque también recetan medicamentos alópatas; g) brujos o hechiceros: son terapeutas muy criticados por las Iglesias católica y adventista, pues su práctica se considera transgresora de sus preceptos religiosos; sus recursos curativos son principalmente tradicionales. 
de los padecimientos infantiles, a la par que recuperaba por medio de entrevistas los sentidos y significados que los informantes les daban; la mitad de las veces requerí la ayuda de una traductora. ${ }^{9}$ En total, hice 55 entrevistas a padres y madres de familia, y 30 a terapeutas, y alrededor de 200 horas de observación participante con los diversos actores. La combinación de técnicas de recolección de datos me permitió contrastar los discursos con las prácticas, así como analizar similitudes y diferencias en el manejo de los casos de defunción y de los casos exitosos.

También utilicé la trayectoria de atención como una herramienta de indagación sobre lo que las familias hicieron desde que detectaron que el niño estaba enfermo hasta que falleció. Este concepto se refiere a la secuencia de decisiones y estrategias instrumentadas por los sujetos para hacer frente a un episodio concreto del padecimiento; incluye la estructura de atención, enfermos, pacientes, terapeutas, otros mediadores y todo tipo de recursos curativos y paliativos empleados (Osorio, 2001).

La información recuperada se codificó y analizó con base en la teoría fundamentada (Auerbach y Silverstein, 2003). Las categorías de análisis se enfocaron en las representaciones sociales y prácticas sobre las causas, signos y síntomas, y tratamientos de los padecimientos que provocaron la muerte de los niños. En total, recuperé siete casos de defunción, pero debido a cuestiones de espacio en este artículo sólo retomo dos que me parecen representativos, uno debido a la tos y otro a la diarrea, pues muestran coincidencias con los demás, que pueden consultarse en el trabajo original (Cortez, 2015).

\section{La trayectoria de atención de Santiago, que murió de diarrea}

Santiago era hijo de Brígida y Urbano, nació el 13 de enero de 2004 y falleció el 30 de marzo de 2005. Tenía un año y dos meses de edad. Era el quinto hijo de esta pareja y el único varón. Brígida relata que cierto día notó que Santiago tenía diarrea y fiebre. Pensó que se trataba de "ojo", padecimiento considerado letal, que no debe tratarse con "ampolleta" porque "no hace efecto el blanquillo", ${ }^{10}$ la terapia tradicional recomendada. Lo primero que hizo fue pasarle el blanquillo por el cuerpo. Horas después repitió la curación sin resultado, así confirmó que no era "ojo" y salió a consultar a doña Josefina, su partera. Ella le dijo que era "diarrea”, le recetó pastillas de Neo-Melubrina —analgésico y antipirético- - antibiliosa y tetraciclina —antibiótico-; le indicó que se las diera molidas y disueltas en agua. Brígida le administró esta mezcla tres veces en un día, la diarrea cesó y pensó que Santiago estaba curado, con lo que dio por terminado el tratamiento.

Urbano explica que dos días después se quedó cuidando a su hijo mientras su esposa y sus hijas iban a cortar leña. Él no podía hacerlo porque estaba recuperándose de un accidente de trabajo que lo dejó en muletas. Cuando ellas regresaron, le pidieron que les comprara un refresco de soda para quitarse la sed y él aceptó. A Santiago "se le antojó” — - tenía ganas de tomar- el refresco y se lo dieron en su biberón. A medianoche, Santiago despertó y "no los dejaba dormir":

Como a la una de la mañana empezó a llorar. Le dije a su mamá que le diera pecho, pero el bebé ya no quería. Le dije a su mamá: "el niño está enfermo,

Trabajar con un hecho del pasado implica tomar cierta distancia del discurso del sujeto, en tanto que la reconstrucción puede verse afectada, de manera consciente o inconsciente, por el proceso de duelo. Por ello traté las trayectorias de atención en varias entrevistas para corroborar la información. Además, contrasté la versión de la madre con la del padre y con la de algún informante secundario si era necesario. Las coincidencias y diferencias, consistencias e inconsistencias, se consideraron significativas, así que se relacionaron con el estatus del sujeto en su familia, el papel que jugó en la trayectoria y las circunstancias económicas y familiares de la muerte.

10 La palabra "blanquillo" hace referencia al huevo de gallina. 
¿será que no le hizo mal el refresco porque estaba muy frío y no le diste pecho?’. [Más tarde] no quería nada, sólo lloraba, le dije a su mamá que lo íbamos a llevar con el doctor, y su mamá me dijo que no porque estaba lloviendo mucho, me decía que lo lleváramos en la mañana cuando ya estuviera bien el clima [...]. A las cuatro o cinco de la mañana ya estaba más jodido porque vomitaba y tenía diarrea [...]; lo agarré porque ya no quedaba, ya no quería nada, ya estaba triste porque le dimos refresco. Pero ya no podíamos hacer nada porque ya le habíamos dado (entrevista con Urbano, Ocotepec, Chiapas, 11 de abril de 2013).

Brígida dice que en un intento de curarlo sacó las pastillas que le había vendido la partera, las molió y se las dio disueltas en agua, pero la terapia no funcionó:

Cuando amaneció, lo llevamos con mi padrino Noé. Nos dijo que ya no lo iba a recibir porque ya estaba grave, porque se iba a morir y le podíamos echar la culpa de que él lo mató. Ya nos preguntó que si estaba enfermo y nos dijo que por qué no lo llevamos desde un día antes [...]. Como mi padrino no lo recibió, lo tuve que llevar en casa de don Gustavo, ni él lo recibió. Me preguntó qué le había dado, y ya le dije que le dimos refresco y ya le contamos [...]. Me dijo que lo lleváramos en la clínica, mi esposa ya no quería ir a la clínica porque decía que allá nos iban a regañar. Como también tengo un tío que es curandero, lo llevamos con él, pero nos dijo que ya no había solución, que si mucho, iba a aguantar 20 o 30 minutos. Dijo que le iba a dar una pastilla, pero que no le echáramos la culpa de la muerte. Le dio Mejoralito, Acromicina, Neo-Melubrina, como diez pastillas le dio, pero de los demás no me acuerdo. Cuando lo trajimos a la casa, mi esposa le preparó todo y le quería dar, pero ya cerraba la boca (entrevista con Urbano, Ocotepec, Chiapas, 11 de abril de 2013).
Cuando le preguntamos por qué no utilizó SRO, ${ }^{11}$ Brígida contestó:

No me acuerdo quién me dijo, pero me dijo pues, no sé si es doña Josefina que me dijo, no sé si es mi pensamiento que... bueno, en la plática siempre lo escuchamos, pues. No sé, la verdad si es mi pensamiento que vino para que yo le dé. No me acuerdo quién es que me dijo, pero sí me dijeron que yo le dé suero y no le quería yo dar. Después le dije a mi esposo: "dame 20 pesos, le voy a comprar al niño el suero", y él: "yo no voy a tocar este dinero, porque este dinero no es mío". ${ }^{12}$ Entonces empecé a pelear con mi esposo, le digo: "¿no le vas a dar 20 pesos al niño? ¿Qué tal que ese suero que le doy le iba a quitar su diarrea?". "Si ya le compraste medicamento, 60 pesos, con eso se le va a quitar". "No, no se le va a quitar", le dije. Pues hasta ahí me quedé en duda, no le di suero, no le di (entrevista con Brígida, Ocotepec, Chiapas, 2 de mayo de 2013).

Media hora después Santiago falleció, dice su mamá que tenía "su labio todo seco".

\section{La trayectoria de atención de Juan, que murió de tos}

Juan nació el 5 de diciembre de 2007 y falleció el 14 de marzo de 2008, tenía 3 meses de edad. Blanca, su mamá, es hija de Brígida y Urbano; Santiago era su hermano. Juan fue su primer hijo. Ella tenía 16 años de edad cuando él nació y se había separado del padre al poco tiempo de quedar embarazada.

En México, las SRO más populares son Vida Suero Oral -"suero"-, que los servicios de salud distribuyen de manera gratuita, pero también puede comprarse en farmacias.

12 El padre había recibido un préstamo para pagar su atención médica, montar un pequeño negocio del que se sostenía la familia y del que tomó una parte para pagar la atención de su hijo. 
Blanca dice que lo primero que detectó en Juan fue "tos". Como era su primer hijo y "no tenía experiencia”, para ella "no era gravedad”. Brígida, la abuela, concuerda en que el primer síntoma fue "tos", por eso "no dejaba dormir a su mamá".

Un curandero que pasó por su casa les dijo que Juan tenía una enfermedad que hace que "se queden viendo para arriba" y que había que conseguir seis velas, "popó de estrella" — una especie de roca que se encuentra en el monte- y huesos de zopilote. Con eso lo curaron durante dos días, sin resultado: "yo pienso que no es de eso, me mintieron porque no se curaba y no miraba arriba. Me dijeron que era porque lloraba bastante, pero no porque de por sí tenía tos" (entrevista con Brígida, Ocotepec, Chiapas, 9 de abril de 2013).

Después, Blanca fue a ver a otra curandera, que le dijo que la cama del niño "estaba encantada", por eso "no lo dejaban dormir". Había que hacerle tres limpias, cada una costaría 100 pesos. A Brígida le pareció muy caro, así que se ofreció a curarlo a cambio de que su hija le comprara un refresco de soda, Blanca aceptó. La curación consistió en bañar a Juan con agua bendita mientras le rezaba: "que Dios te cuide y que dios te bendiga porque tú no eres bautizado todavía". También regó la casa con agua bendita y "le puso hierbas en el pechito". Repitió este tratamiento durante tres días y con eso "se calmó".

Sin embargo, Juan seguía con tos, pero Blanca no tenía dinero para llevarlo a curar y tuvo que esperar cinco días a que le pagaran a su padre. Cuando esto sucedió, decidió llevarlo con don Gustavo, un practicante que le inyectó un medicamento, le puso supositorios para bajarle la fiebre y le recetó dos jarabes, uno de ellos era ambroxol. No recuerda cuál era el otro. Ella tenía que volver a darle el jarabe una hora después "porque eso es que le iba a sacar toda la flema".

Blanca dice que este tratamiento "complicó" el cuadro, "le dio como ataque, le salió calambre, empezó a temblar", y así pasó la noche, "temblaba y sus ojos se le iban para atrás". Blanca y los abuelos decidieron suspender el tratamiento porque "ya estaba así, temblando”. Ella le peguntó a sus papás: “¿qué es que voy a hacer?”. Urbano le dijo que no se preocupara, que lo llevaría a curar.

Al día siguiente, los abuelos lo llevaron a un pueblo cercano, con un espiritista que les advirtió que Juan "iba a morir, no se iba a componer", porque en un sueño lo habían "maltratado" debido a la "envidia” que le tenían por ser varón. El señor regañó a los abuelos por no haber llevado a la madre, puesto que tenía que haberle curado el pecho. Le hizo una limpia con sahumerio y hierbas a Juan, y recomendó que le hicieran otra con huevos de pato y pavo. Los abuelos no le dijeron a Blanca que Juan iba a morir. Aun así, le pasaron los huevos tres veces, pero no mejoró.

Blanca dice que a la mañana siguiente se fue sola a la clínica y que Juan "como que se hizo todo morado". El médico le dijo que le daría su "pase" — hoja de referencia - para el Hospital Regional de Tuxtla Gutiérrez, pero advirtió: "a ver si llega todavía el niño, porque ya está bien grave”, y le puso una ampolleta. Blanca desconoce qué medicamento era. De inmediato, ella regresó a su casa para preguntar a sus padres si la apoyarían para trasladar al bebé. El abuelo respondió que sí, pero Juan falleció minutos después.

\section{Los saberes maternos como determinantes de la búsqueda de atención apropiada}

Estas trayectorias describen las representaciones sociales y las prácticas de atención de la EDA y la IRA. Aunque no es posible ahondar en ellas, analizaré las que me parecen más importantes para los desenlaces. ${ }^{13}$

En las entrevistas a las informantes se observa que las representaciones sociales sobre las causas de

Una amplia descripción y análisis de los saberes de las madres y terapeutas ocotepecanos, sobre todos los padecimientos infantiles que reconocen, puede consultarse en mi tesis doctoral. 
la diarrea son: "comer tierra", "el calor o la frialdad del tiempo", el "traspaso" — no dar de comer al niño a las horas debidas - y los parásitos. Además, es signo de otros padecimientos, como la "caída de mollera" y el "antojo", y puede presentarse sola o acompañada de fiebre y vómito, que se identifican y también se atienden. Sin embargo, la deshidratación no se menciona como algo que deba evitarse cuando empiezan las evacuaciones.

En el caso de Santiago, los primeros síntomas que la madre detectó fueron diarrea y fiebre, que diagnosticó como “ojo”, contra el que empleó una terapia tradicional. Al no tener éxito, consultó a una partera. Ésta recetó un antipirético y un antibiótico muy potente, el uso de este último no se justifica por completo en este caso y contraviene las recomendaciones internacionales respecto a la terapia para la diarrea. Aunque la autopsia verbal no permite saber si el cuadro ameritaba el antibiótico, es evidente que su uso no fue apropiado porque dos días después el paciente recayó, lo que se explica en parte porque fue suspendido a las 24 horas, ${ }^{14}$ debido a que la madre pensó que se había curado cuando desaparecieron los síntomas. Sin embargo, el factor que parece más peligroso es que no se utilizaron SRO.

En las entrevistas encontré que las pocas informantes que usan SRO en casos de diarrea no lo hacen por iniciativa propia, sino por prescripción de algún practicante o partera. En otro trabajo encontré que las mujeres percibían que éstas eran ineficaces. Decían: "no le hace nada", o bien, que eran nocivas, o “sale más diarrea" (Cortez, 2011). Esto se debe a que para ellas es indispensable que desaparezcan los síntomas para percibir su eficacia pragmática, lo que no hacen las SRO, pues su función no es ésa sino evitar la deshidratación. Esto explica el hecho de que Brígida "no le confiaba" y por eso no las usó, aunque quizá la partera o su "pensamiento" la instaban a hacerlo. ${ }^{15}$

Otras informantes, al igual que Brígida, mencionaron que para curar la diarrea usan antiespasmódicos, antipiréticos, antibióticos y antieméticos, lo que parece ser una práctica extendida. Sólo una de ellas dijo que, "cuando no hay dinero", usa el té de guayaba. Brígida también mencionó que 15 años antes un curandero le recetó el caldo de un gallito para curar a su hija de diarrea, tratamiento que ella había empleado en fechas recientes para curar a una sobrina. Las demás informantes no aludieron al uso de tés o caldos.

Dos días después de que fueran detectados los primeros síntomas, Santiago presentó muchas evacuaciones, fiebre y vómito, lo que le causó una deshidratación severa. Esto último se concluye por signos como el rechazo del alimento, el llanto constante, los labios secos y el verse "triste", alarmantes desde el punto de vista de la literatura biomédica, pero inadvertidos por los padres, quienes no percibieron el riesgo de deshidratación sino que estaban preocupados por la diarrea, el vómito y la fiebre; y en un intento desesperado, la madre administró otros medicamentos para curarlos, pero no SRO.

Cuando Santiago llegó con los practicantes don Noé y don Gustavo, era muy tarde. Ambos rechazaron atenderlo porque su defunción era inminente y no querían ser acusados de iatrogenia. ${ }^{16}$ En un último momento, la madre quiso darle el "suero" pero su esposo le negó el dinero. A estas alturas era difícil que le ayudara, pues la vida de Santiago estaba comprometida desde horas antes.

La trayectoria de tos tuvo una evolución de diez días. En las entrevistas encontré que "la frialdad del tiempo" y "no abrigar a los niños" se

14 La literatura médica explica que la suspensión abrupta de los antibióticos es perjudicial porque genera resistencia bacteriana, con lo que los síntomas pueden reaparecer y tornarse más agudos (Unicef y wHO, 2006).

15 En la actualidad, Brígida usa las SRO por iniciativa propia y explica que sirven para "reponer los líquidos" que se pierden con la diarrea.

16 En Ocotepec, una acusación de este tipo podría representar una demanda ante el juez, para compensar los daños con una penalización económica. Además, implicaría que los afectados difundieran la iatrogenia cometida, con lo que el curador podría perder pacientes. 


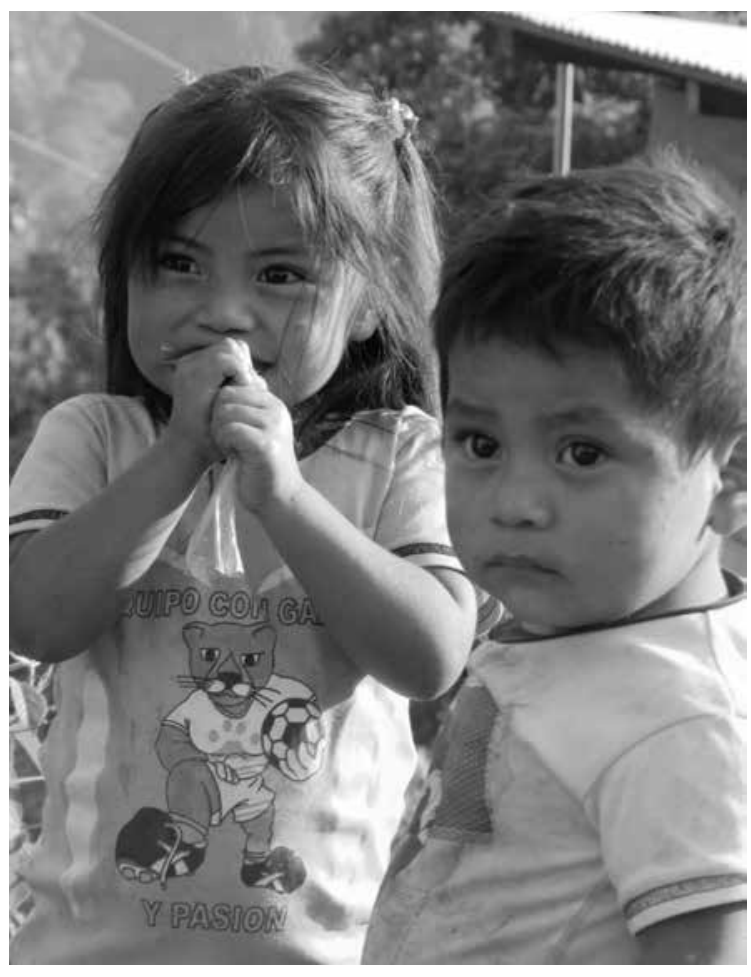

Renata Gabriela Cortez Gómez • Niños zoques.

concebían como factores causales de la tos, pero en el caso de Juan, se señalan la agencia sobrenatural — "los duendes encantaron la cama" - y la agencia humana - la "envidia” y la iatrogenia cometida por un curador-. Dos informantes mencionaron que la tos es peligrosa porque a los niños "se les tapa la nariz o la garganta y no pueden respirar”, es decir, sí identifican la dificultad respiratoria como un signo de alarma, aunque no la consideran indicativo de neumonía. Brígida y Blanca no mencionaron que Juan presentara dificultad respiratoria, lo que sugiere que no la reconocieron.

Las informantes refirieron el uso de antibióticos, antipiréticos y antihistamínicos para curar la tos y la fiebre, que compran en las farmacias o son prescritos por parteras o practicantes. En menor medida refirieron terapias tradicionales para bajar la fiebre. En el caso de Juan, recursos tradicionales y alópatas se intercalaban conforme se probaban y descartaban. Los primeros diagnósticos fueron padecimientos no reconocidos por la medicina alópata, "ver para arriba" y "cama encantada", que se atendieron con limpias ineficaces; por esta razón, la infección respiratoria siguió su evolución natural.

Unos días después, un practicante recetó un expectorante - ambroxol-, un antipirético —supositorio-y un antibiótico — "ampolleta"—. ${ }^{17}$ Sin embargo, el estado de Juan ya era crítico porque presentó convulsiones horas más tarde - “temblaba", "los ojos se le iban para atrás"- La madre y los abuelos no se percataron de la evolución del cuadro de tos a neumonía, evidente por los signos que se desplegaban. En cambio, asociaron las convulsiones a una iatrogenia médica causada por el uso de la "ampolleta". Incluso hoy en día tienen una representación negativa de la "ampolleta", cuando en realidad la administración de un antibiótico es indispensable si se trata de neumonía (Unicef y WHO, 2006). No obstante, lo más seguro es que a esas alturas Juan requiriera hospitalización. ${ }^{18}$ La percepción de iatrogenia los llevó a suspender el tratamiento. El espiritista advirtió que el estado de Juan era crítico, pero prescribió terapias ineficaces - las limpias- . A falta de una terapia apropiada y de hospitalización, que no fue sugerida por el practicante ni por el espiritista, Juan presentó una insuficiencia respiratoria que le provocó cianosis — "se puso morado"-. Cuando llegó a "la clínica", era demasiado tarde.

La observación participante y las entrevistas con los médicos practicantes revelaron que las ampolletas con frecuencia son antibióticos, como la ampicilina.

18 En 2012, otro hijo de Blanca enfermó de neumonía a los 15 días de nacido. Aunque Brígida le aconsejó que se quedara en Ocotepec mientras ella llevaba a su otra nieta a la consulta que tenía programada en el Hospital Regional de Tuxtla Gutiérrez, Blanca decidió ir con ellas y solicitar atención. El acceso no fue fácil porque no llevaban hoja de referencia; sin embargo, ante la insistencia de la abuela, el personal permitió la hospitalización del niño, que fue dado de alta 15 días después. 


\section{La medicalización y la mercantilización de las prácticas médicas locales y la falta de acceso al primer nivel de atención}

Las trayectorias coinciden en que los diagnósticos se reformulaban conforme los tratamientos se suspendían, cambiaban y se repetían según se probaban, o se descartaban si se consideraban nocivos o ineficaces. Osorio (2001) determina que estas conductas son propias de los saberes maternos que funcionan con una racionalidad de ensayo y error, es decir, que son pragmáticos, y si bien pueden resultar efectivos, también pueden ocasionar iatrogenias.

En las trayectorias, la diarrea, la tos y la fiebre se codificaron como signos de enfermedad que había que desaparecer, pero no se advirtieron sus consecuencias más peligrosas: la deshidratación y la neumonía. Esto desvió la atención de la necesidad de utilizar SRO para prevenir la primera y un antibiótico oportuno para curar la segunda. Aunque en el primer caso la partera se lo recetó a Brígida, ella "no le confiaba al suero". Por otro lado, Juan recibió un antibiótico cuando su estado era crítico y requería hospitalización; pero antes de eso sólo recibió terapias tradicionales ineficaces que facilitaron la evolución natural de la IRA. Santiago tampoco mejoró con la terapia contra el "ojo” y el uso inapropiado del antibiótico fue nocivo.

Problemas como éstos en el tratamiento de la IRA y la EDA han sido encontrados en los contextos mexicano (Álvarez-Larrauri, 1998; Ferreira, Mongua y Díaz, 2013; Ferreira, Báez y Trejo, 2013) y mundial (OPS, 2006; Unicef y WHO, 2006). Para el caso de la diarrea, se ha subrayado lo siguiente:

Prevenir la deshidratación administrando, ante la primera señal de diarrea, una mayor cantidad de líquidos disponibles en el hogar y la solución de SRO, si está a mano. Continuar la lactancia materna o la alimentación habitual del niño durante el episodio. Reconocer los signos de deshidratación y llevar al niño a un centro de salud para que le administren las nuevas SRO o una solución intravenosa de electrolitos, y familiarizarse con otros síntomas que requieren tratamiento médico (por ejemplo, deposiciones diarreicas con sangre) (OPS, 2006: 2-3).

Estudios hechos en México han encontrado que los padres o cuidadores, si bien identifican el aumento en la frecuencia de evacuaciones y la presencia de vómito y fiebre como signos de alarma de la EDA, no reconocen otros que indican deshidratación o diarrea invasiva, como el llanto sin lágrimas o la presencia de sangre en las heces. Además, se ha encontrado una menor proporción del uso de SRO por parte de los padres o cuidadores en relación con décadas previas, y una tercera parte de ellos mencionó que brindó una menor cantidad de alimentos a los niños durante los episodios diarreicos (Ferreira, Mongua y Díaz, 2013). Estos datos sugieren que la probabilidad de que a los niños se les dé una atención deficiente es alta, como sucedió con Santiago.

Asimismo, los estudios sobre el reconocimiento de signos de alarma de la IRA identificados por padres o cuidadores mexicanos reportan que los más frecuentes son: "más de tres días con calentura", "se ve más enfermo" y "no come ni bebe”. Sin embargo, la identificación de la neumonía en signos como "respira rápido" y "no puede respirar" es menos frecuente (Ferreira, Báez y Trejo, 2013). Esto coincide con estudios internacionales que determinan que sólo la mitad de los niños con neumonía recibe atención apropiada y sólo 19\% con antibióticos, pero en las zonas rurales o cuando son hijos de madres sin escolaridad esto es menos frecuente, por lo tanto, el riesgo de muerte se incrementa (Unicef y WHO, 2006). El tratamiento recomendado internacionalmente contra la neumonía consiste en: 1) reconocer que el niño está enfermo; 2) buscar atención apropiada; 3) tratarlo con los antibióticos adecuados (Unicef y WHO, 2006). En los casos de defunción por neumonía, encontré que no se buscó 
atención apropiada desde el comienzo, como es evidente en el de Juan.

Las formas locales de entender los padecimientos, que se aprecia en los diagnósticos de "ojo”, “cama encantada" y "ver para arriba”, motivaron el uso de recursos terapéuticos tradicionales ineficaces, por ello es necesario resaltar el papel que juegan los saberes de las madres y curanderos en la no prevención de la deshidratación y en la dilación en la búsqueda de atención apropiada de la IRA.

Aunque luego intervienen otros terapeutas más familiarizados con la medicina alópata, el uso de los antibióticos no fue apropiado. Por un lado, se aprecia una situación que ha sido denunciada en México y ha llevado a un control más estricto en la venta de estas sustancias: su uso injustificado y la suspensión abrupta del tratamiento, lo que genera resistencia bacteriana. Esto pudo haber ocurrido en el caso de Santiago. Por otro lado, en el caso de Juan, se aplicó tarde, y por lo mismo, fue insuficiente para curarlo.

El uso extendido de fármacos en Ocotepec refleja un proceso de medicalización; con esto me refiero a una mayor recurrencia a medicamentos de patente para curar los padecimientos, cuando hay recursos tradicionales que podrían utilizarse de forma paralela o exclusiva. Este uso fue promovido hace décadas por grupos adventistas y católicos - porque el mejoramiento de la salud de la población era parte de su proyecto evangelizador-, por las agencias gubernamentales - IMSS-Coordinación General del Plan Nacional de Zonas Deprimidas y Grupos Marginados (Coplamar), INI-, con programas de capacitación para médicos tradicionales, y por los "doctores", que los prescribían a los usuarios de "la clínica" (Cortez, 2015). De hecho, otros estudios han encontrado que los médicos institucionales y privados prefieren el uso de antibióticos, antieméticos, antidiarreicos y antiparasitarios para tratar la diarrea, antes que las SRO (Aceituno et al., 1994, citado en Álvarez-Larrauri, 1998), por ello no se descarta que los "doctores" de Ocotepec promovieran poco el uso de SRO y favorecieran el uso de fármacos.

Esta medicalización es nociva para la atención de la diarrea, por el uso inapropiado de antibióticos y porque se descarta el uso de tés o caldos para reponer los líquidos perdidos en las evacuaciones (Ferreira, Mongua y Díaz, 2013). Coincido con Álvarez-Larrauri (1998) en que, además de la eficacia pragmática que los fármacos han demostrado, opera una eficacia simbólica. Los ocotepecanos asocian el uso de fármacos a la curación de las diarreas, cuando la mayoría de éstas son autolimitadas y no requieren medicación. Esto pudo haber favorecido su uso, aunque fuera innecesario.

Entre los agentes de la medicalización también están los curanderos. Las informantes mencionaron dos razones importantes para consultarlos: 1) que no aplican "ampolletas", consideradas nocivas para los niños, sino que usan pastillas o hierbas, a las que perciben como inocuas, y 2) que sus tarifas son más económicas que las de los practicantes, que además usan "ampolletas". Por su parte, los practicantes aceptaron que "cobran más" porque tienen que comprar los medicamentos que prescriben, mientras que los curanderos "encuentran" las hierbas "en el monte" (entrevistas con un partero y un practicante, Ocotepec, Chiapas, 8 de agosto y 12 de septiembre de 2012, respectivamente). La mercantilización de las prácticas médicas locales, que algunas décadas atrás no sucedía, las hace menos asequibles para una población que con frecuencia no dispone de dinero en efectivo para llevar a los niños a consulta. En el caso de Juan, se observa que Blanca no tenía para pagarle a la curandera y tuvo que esperar cinco días para llevarlo con el practicante. En el de Santiago, Brígida quiso comprarle un "suero" pero su esposo no le dio dinero porque el que tenía "no era de él". Esto comprueba que la mercantilización retrasa la atención oportuna.

No obstante, en la localidad hay una "clínica" que ofrece consulta gratuita, pero en ninguno de los 
casos fue la primera opción. El análisis de las entrevistas determinó que la organización de la atención en la clínica dificulta el acceso y por ello los informantes no la consideran una alternativa real de atención. Esto tiene su explicación en las representaciones sociales negativas de los informantes respecto de las relaciones médico-paciente — dicen que "los regañan"- y enfermera-paciente — dicen que ella "no les hace caso"-, el prestigio y la capacidad técnica —dicen que "no curan o no atienden"-, la accesibilidad — dicen que "hay que sacar ficha" y esperar horas para la consulta — y la disponibilidad — los horarios son restringidos y sólo hay una médica-, algo que se ha construido históricamente desde que la clínica abrió.

Esto contrasta con la atención que proporcionan practicantes, curanderos y parteras, a los que pueden buscar directo en su domicilio, sin "sacar ficha" o esperar horas para recibir consulta (entrevistas con informantes).$^{19}$ Por estas razones, dichos terapeutas constituyen el segundo nivel de atención, después de la autoatención. Coincido con Menéndez (1990) en que lo último juega un papel fundamental como instancia que detecta, diagnostica y decide cómo o dónde atenderse, como se ha demostrado.

Si bien la práctica de curanderos y espiritistas demuestra las limitaciones reales de la medicina tradicional para curar ciertos padecimientos, y la de practicantes y parteras presenta algunos problemas, son ampliamente consultados por las mujeres. Sin embargo, ninguno está contemplado en las estrategias de atención primaria de los servicios de salud en la praxis, aunque sí en el nivel normativo (Secretaría de Salud, 2015). Esta exclusión práctica por parte del personal de la clínica impide un trabajo coordinado que coadyuve a la canalización oportuna de niños con signos de alarma. Esto contrasta con el trabajo que se hace con las parteras, quienes realizan una labor importante al detectarlos de inmediato en mujeres embarazadas, referirlas y acompañarlas al segundo nivel de atención para evitar muertes maternas. ${ }^{20}$
He descrito que practicantes y curanderos envían a los usuarios a la clínica cuando reconocen signos de alarma que indican un estado crítico, pero lo hacen para evitar los problemas comunitarios que conlleva. Respecto al personal de la clínica, no muestra interés por promover un trabajo intersectorial para evitar muertes de menores de cinco años, aun cuando se sabe de la existencia de otros terapeutas locales y de cómo absorben gran parte de la demanda de atención médica. ¿Acaso es necesario que la defunción de un niño se penalice como la muerte materna para que esto motive acciones preventivas y resolutivas sectoriales e intersectoriales?

\section{Consideraciones finales}

Las políticas públicas mexicanas para reducir las muertes de niños menores de cinco años por EDA e IRA tuvieron resultados positivos; sin embargo, existen lugares donde estas enfermedades aún provocan la mayoría de las defunciones entre este grupo de edad. Desde la perspectiva de la epidemiología sociocultural, la alta proporción de muertes por causas susceptibles de ser prevenidas es un reflejo de la desigualdad de Ocotepec respecto a la sociedad nacional y —agregaría - de las limitaciones o deficiencias de las políticas públicas.

El análisis de la autoatención a partir de los saberes maternos demuestra que en Ocotepec hay formas locales de entender y atender los padecimientos infantiles, que se mezclan e intercalan con otras nociones y recursos terapéuticos alópatas,

19 Una partera y su hija, Ocotepec, Chiapas, 13 de marzo de 2013; padre de un niño fallecido, Ocotepec, Chiapas, 18 de diciembre de 2012.

20 Durante el trabajo de campo observé que la ocurrencia de una defunción materna en Ocotepec generó la movilización de diversas instancias del Sector Salud federal y estatal para esclarecerla y deslindar responsabilidades (notas del diario de campo). 
problemáticos para la prevención de la deshidratación y la atención de la neumonía. En el caso de la primera porque sólo se reconocen signos como la diarrea, el vómito y la fiebre, que tratan de contrarrestarse con medicamentos, sin considerar la necesidad de reponer los líquidos que el niño pierde en las evacuaciones. En el caso de la neumonía, aunque se identifican la tos, la fiebre y la dificultad respiratoria, no se busca la atención apropiada de forma inmediata, lo que favorece la complicación de la IRA.

A estos problemas hay que sumar otros procesos que dificultan la atención, como la medicalización y la mercantilización de las prácticas médicas locales, y la falta de acceso real a la clínica. Estos procesos hacen vulnerables a las familias que desconfían de ciertos recursos terapéuticos, como las "ampolletas" y las SRO, que no tienen dinero para pagar un terapeuta o que viven lejos de los servicios públicos de salud, con lo que disminuyen las probabilidades de que proporcionen atención oportuna y apropiada a sus hijos.
Considero que es necesario diseñar estrategias de prevención y atención a la EDA y la IRA que recuperen los saberes maternos, para identificar con qué otros padecimientos se asocian los signos de alarma y cómo se atienden, de modo que se pueda capacitar a las madres en la identificación puntual de la deshidratación y la neumonía, y diferenciarlas de otros padecimientos. También es necesario que doctores, practicantes, parteras y curanderos uniformen sus tratamientos con base en las recomendaciones internacionales para socializar el uso de las SRO y hacer uso apropiado de los antibióticos. Además, es necesario diseñar estrategias intersectoriales para canalizar de manera oportuna a los niños que necesitan hospitalización por deshidratación o neumonía.

La muerte es un fenómeno multifactorial, pero considero que este análisis de los saberes maternos puede dar algunas pistas para plantear investigaciones en contextos en los que todavía la EDA y la IRA constituyen causas importantes de muerte de niños, pese a los programas implementados para su prevención. D

\section{Bibliografía}

Álvarez-Larrauri, Selene, 1998, “Las prácticas maternas frente a la enfermedad diarreica infantil y la terapia de rehidratación oral”, en Salud Pública de México, vol. 40, núm. 3, pp. 256-264.

Auerbach, Carl F. y Louise B. Silverstein, 2003, Qualitative Data. An Introduction to Coding and Analysis, New York University Press, Nueva York. Comité Estatal de Información Estadística y Geográfica de Chiapas (CEIEG), 2014, "Perfiles municipales: Ocotepec". Disponible en línea: <http://www.ceieg.chiapas.gob.mx/perfiles/Inicio>. Consultado el 15 de diciembre de 2014.

Consejo Nacional de Evaluación de la Política de Desarrollo Social (Coneval), 2012, Informe de pobreza en México. El país, los estados y sus municipios 2010, Consejo Nacional de Evaluación de la Política de Desarrollo Social, México.

Consejo Nacional de Población (Conapo), 2011, "Tasa de mortalidad infantil por municipio”, en Estimación de la mortalidad infantil para México, las entidades federativas y los municipios 2005, Consejo Nacional de Población, México. Disponible en línea: <http://www. conapo.gob.mx/es/CONAPO/Base_de_datos>. Consultado el 6 de noviembre de 2011.

Cortez Gómez, Renata Gabriela, 2011, Desnutrición y familia. Representaciones sociales y prácticas de autoatención a la desnutrición infantil y proceso alimentario en familias ocotepecanas, tesis de maestría en antropología social, Centro de Investigaciones y Estudios Superiores en Antropología Social, México.

—_ 2015, Muerte de niños menores de cinco años. Desigualdad étnica, económica y de género como condicionantes de la autoatención en familias zoques, tesis de doctorado en antropología, Centro de Investigaciones y Estudios Superiores en Antropología Social, México.

Fernández Cantón, Sonia, Ana María Hernández Martínez y Ricardo Viguri Uribe, 2013, "Mortalidad en población de menores de cinco años en México durante 2011", en Boletín Médico del Hospital Infantil de México, vol. 70, núm. 1, pp. 67-70.

Ferreira Guerrero, Elizabeth, Norma Mongua Rodríguez y José Luis Díaz Ortega, 2013, "Diarreas agudas y prácticas de alimentación en niños menores de cinco años en México", en Salud Pública de México, vol. 55, supl. 2, pp. S314-S322.

Ferreira Guerrero, Elizabeth, Renata Báez Saldaña y Belem Trejo Valdivia, 2013, "Infecciones respiratorias agudas en niños y signos de alarma identificados por padres y cuidadores en México”, en Salud Pública de México, vol. 55, supl. 2, pp. S307-S313. 
Haro, Jesús Armando, 2008, "Etnicidad y salud. Estado del arte y referentes del noroeste de México", en Región y Sociedad, vol. XX, núm. especial 2, pp. 265-313.

Hersch-Martínez, Paul, 2013, “Epidemiología sociocultural: una perspectiva necesaria”, en Salud Pública de México, vol. 55, núm. 5, pp. 512-518. Instituto Nacional de Estadística, Geografía e Informática (INEGI), 2004, La mortalidad infantil en México 2000. Estimaciones por entidad federativa y municipio, Instituto Nacional de Estadística, Geografía e Informática, México.

—_, 2011, "Chiapas", en Censo de Población y Vivienda 2010. Principales resultados por localidad, Instituto Nacional de Estadística y Geografía, México.

—_, 2013, Panorama sociodemográfico de los 125 municipios con menor IDH, Instituto Nacional de Estadística y Geografía, México.

__ 2016, "Principales causas de mortalidad por residencia habitual, grupos de edad y sexo del fallecido: Chiapas". Disponible en línea: <http://www.inegi.org.mx/est/contenidos/proyectos/registros/vitales/mortalidad/tabulados/ConsultaMortalidad.asp>. Consultado el 15 de mayo de 2016.

Instituto Nacional de Salud Pública (INSP), 2012, Encuesta Nacional de Salud y Nutrición 2012, Instituto Nacional de Salud Pública, México.

Kleinman, Arthur, 1980, "Orientations 2: Culture, Health Care Systems, and Clinical Reality", en Arthur Kleinman, Patients and Healers in the Context of Culture: An Exploration of the Borderland between Anthropology, Medicine and Psychiatry, University of California Press, Berkeley, pp. 24-70.

Menéndez, Eduardo, 1990, Antropología médica: orientaciones, desigualdades y transacciones, Centro de Investigaciones y Estudios Superiores en Antropología Social, México.

Organización de las Naciones Unidas (ONU), 2015, Objetivos de Desarrollo del Milenio, Informe de 2015, Organización de las Naciones Unidas, Nueva York.

Organización Panamericana de la Salud (OPS), 2006, Nuevas recomendaciones para el tratamiento clínico de la diarrea. Políticas y guías programáticas, Organización Panamericana de la Salud, Washington, D.C.

Osorio Carranza, Rosa María, 2001, Entender y atender la enfermedad. Los saberes maternos frente a los padecimientos infantiles, Instituto Nacional Indigenista/Instituto Nacional de Antropología e Historia/Centro de Investigaciones y Estudios Superiores en Antropología Social, México.

Secretaría de Salud, 2015, Marco legal de la medicina tradicional y las medicinas complementarias, Dirección de Medicina Tradicional y Desarrollo Intercultural- Subsecretaría de Innovación y Calidad-Dirección General de Planeación y Desarrollo en Salud-Secretaría de Salud. Disponible en línea: <http://www.lacasadedonbasilio.mx/documents/marco_legal.pdf>. Consultado el 3 de enero de 2015.

Dirección General de Información en Salud (DGIS), 2016, Bases de datos sobre defunciones. Disponible en línea: <http://www.dgis.salud.gob. $\mathrm{mx} /$ contenidos/basesdedatos/std_defunciones.html>.

Tapia, Roberto, 2007, “Aumento de la sobrevida en menores de cinco años en México: la estrategia diagonal”, en Salud Pública de México, vol. 49, supl. 1, pp. 110-125.

United Nations Children's Fund (Unicef), 2014, Levels and Trends in Child Mortality. Report 2014, United Nations Children's Fund/World Health Organization/The World Bank/United Nations, Department of Economic and Social Affairs, Population Division/United Nations Economic Commission for Latin America and the Caribbean, Population Division, Nueva York.

United Nations Children's Fund (Unicef) y World Health Organization (WHO), 2006, Pneumonia, the Forgotten Killer of Children, United Nations Children's Fund/World Health Organization, Nueva York.

World Bank, The, 2015, "Mortality Rate, Under-5 (Per 1000 Live Births)". Disponible en línea: <http://data.worldbank.org/indicator/SH.DYN. MORT>. Consultado el 16 de enero de 2015.

\section{Entrevistas}

Brígida, Ocotepec, Chiapas, 9 de abril y 2 de mayo de 2013.

Enfermera de la unidad médica rural, Ocotepec, Chiapas, 26 de noviembre de 2012.

Enfermera del Imss-Oportunidades, Ocotepec, Chiapas, 26 de noviembre de 2013.

Informantes: una partera y su hija, Ocotepec, Chiapas, 13 de marzo de 2013; padre de un niño fallecido, Ocotepec, Chiapas, 18 de diciembre de 2012. Médica de la unidad médica rural, Ocotepec, Chiapas, 20 de diciembre de 2012.

Partero, Ocotepec, Chiapas, 8 de agosto de 2012.

Practicante, Ocotepec, Chiapas, 12 de septiembre de 2012.

Urbano, Ocotepec, Chiapas, 11 de abril de 2013. 